\title{
Influence of Climate Change on Maize Yield in Growing Season-A Case Study of the Songliao Plain
}

\author{
Guna Ari ${ }^{1}$ Jiquan Zhang ${ }^{1, *}$ Yulong $\mathrm{Bao}^{2} \mathrm{Hanfu} \mathrm{Asi}^{2}$ \\ ${ }^{1}$ School of Environment, Northeast Normal University, Key Laboratory for Vegetation Ecology, Ministry of \\ Education, Changchun 130117, China \\ ${ }^{2}$ School of Geographical Sciences, Inner Mongolia Normal University, Hohhot 010022 \\ *Jiquan Zhang. Email: zhangjq022@nenu.edu.cn
}

\begin{abstract}
With global warming, extreme weather and climate events, such as super-severe drought, are occurring more frequently, affecting more and more, and damaging more and more, which makes the distribution range of drought disasters and the impact of agricultural ecology more extensive. In order to analyze the climate change characteristics and its impact on corn yield in Songliao Plain under the background of global climate change, based on the temperature and precipitation data of 18 meteorological stations in Songliao Plain from 1965 to 2018, the Coupled Model Intercomparison Project Phase 5( CMIP5) data and corn yield data from 1981 to 2018, the drought change characteristics in Songliao Plain were analyzed by using standardized precipitation evapotranspiration index (SPEI), and the meteorological factors, drought index and corn climate were discussed in combination with correlation analysis. The results are as follows: 1) during the growing season of Songliao Plain from 1965 to 2018, the temperature increased and the precipitation decreased. In terms of geographical spatial distribution, Harbin, Liaoyang and Anshan had the highest temperature increase, while the precipitation decreased the most in the southeast of Songliao Plain. Overall, it shows the trend of drought. 2) From 1981 to 2018, the climatic yield of maize was positively correlated with SPEI-1 and SPEI3, compared with SPEI-1, the correlation between SPEI-3 is stronger. The greater the drought index, the higher the climate yield. 3) Under the scenario of global warming of $1.5^{\circ} \mathrm{C}$ and $2.0^{\circ} \mathrm{C}$, the temperature and precipitation in the growth season of Songliao Plain have increased compared with the reference period (1976-2005), showing a warm and dry trend. This study provides a scientific basis for the formulation and implementation of early warning, prevention and response measures of agricultural drought in this region.
\end{abstract}

Keywords: Climate change, Maize yield, SPEI, Songliao plain

\section{生长季气候变化对玉米产量的影响一以松辽平原为例}

\section{阿日古娜 1 张继权 ${ }^{1 *}$ 包玉龙 ${ }^{2}$ 阿斯汉夫 ${ }^{2}$}

\author{
1 东北师范大学 环境学院 东北师范大学自然灾害研究所 长春 130117 \\ 2 内蒙古师范大学 地理科学学院, 呼和浩特 010022 \\ *张继权. 电子邮箱:zhangjq022@nenu.edu.cn
}




\section{摘要}

随着全球变暖, 超强特大干旱等极端天气气候事件发生的频率越来越高, 影响范围越来越大, 破坏程度越来越 强, 使干旱灾害的分布范围和农业生态的影响更广泛。为了分析全球气候变化背景下松辽平原玉米生长季气候 变化特征及其对产量的影响, 本文基于松辽平原 1965-2018 年 18 个气象站点气温降水数据、耦合模式比较计 划第五阶段(CMIP5)数据和 1981-2018 年玉米产量数据, 利用标准化降水蒸散指数(SPEI)分析了松辽平原干旱 变化特征，并结合相关分析探讨了气象因子、干旱指数与玉米气候产量之间的关系的同时结合全球变暖 $1.5^{\circ} \mathrm{C}$ 和 $2.0^{\circ} \mathrm{C}$ 预估未来的干旱情况。结果表明：1）1965-2018 年松辽平原生长季气温呈上升趋势，降水呈下降趋势， 地理空间分布上，哈尔滨市、辽阳市和鞍山市的升温幅度最高，松辽平原东南部地区降水减少幅度最大。总体 表现干旱化趋势。2）1981-2018 年玉米气候产量与生长季 SPEI-1 和 SPEI-3 成正相关, 相对 SPEI-1 与 SPEI-3 的相关性更强。干旱指数越大，气候产量越高。3）全球升温 $1.5^{\circ} \mathrm{C}$ 和 $2.0^{\circ} \mathrm{C}$ 情景下，松辽平原生长季气温和降 水相对基准期(1976-2005 年)都有上升，有暖干旱趋势。本研究为该地区政府农业旱灾预警预防、应对措施的 制订和实施提供科学依据。

关键词: 气候变化, 玉米产量, SPEI, 松辽平原

\section{1.引言}

政府间气候变化专门委员会 (IPCC) 第四次评估 报告 ${ }^{[1]}$ 指出, 近百年来地球正经历着以全球变暖为特 征的显著变化。IPCC 第五次评价报告, 全球平均表

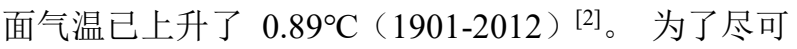
能避免全球变暖对生态环境可能带来的危害, 2015 年 12 月 12 日经过各领域专家、学者商议一致通过 了《巴黎协定》, 该协定明确提出要将全球温度上升 幅度控制在 $2.0^{\circ} \mathrm{C}$ 之内, 并尽量限制在工业化水平以 上 $1.5^{\circ} \mathrm{C}$ 之内。在全球气候变暖和社会经济高速发展 的影响下,全球灾害问题尤为突出, 其中最为严峻的问 题之一是干旱频繁发生及强度增加, 干旱已经成为全 球性问题 ${ }^{[3]}$ 。不稳定的全球气候变化会导致农业生产、 生态环境和社会经济发展的不稳定性增加或减少, 并 给人类生活带来了巨大的风险。旱灾与地球环境相伴 而生, 是气候系统自然波动的必然产物 ${ }^{[4-5]}$ 。1960 至 2015 年, 我国因旱灾造成的受灾面积高达 $1391 \mathrm{~km}^{2}$, 成 灾面积 $631 \mathrm{~km}^{2}$ 。

松辽平原是我国最大平原的一部分,研究区面积 17.4 万 $\mathrm{km}^{2}$ 。它在确保我国粮食安全方面发挥着举足 轻重的作用。而近几十年来松辽平原气候变化显著, 对该地区的玉米生产已经产生了明显的影响。松辽平 原中部 55\%的粮食减产是由农业气象灾害造成的。因 此, 应对气候变化背景下农业干旱已成为灾害风险管 理的新特征和新挑战。

\section{2.研究区概况}

松辽平原地处中国东北部, 位于 $40^{\circ} 12^{\prime} \sim 46^{\circ} 18^{\prime} \mathrm{N}$, $120^{\circ} 42^{\prime} \sim 127^{\circ} 36^{\prime} \mathrm{E}$, 包括黑龙江省南部、吉林省的中 西部、辽宁省的大部分地区和内蒙古东北部，整个区 域在行政区划上划分为 17 个地级市(图 1)。松辽平原 处于温带和暖温带范围, 有大陆性和季风性气候特征。 夏季炎热多雨, 冬季寒冷干燥, 年平均温度 $3 \sim 8^{\circ} \mathrm{C}$, 最冷月平均温度 $-12 \sim-18^{\circ} \mathrm{C}$, 最热月平均温度 $22 \sim$ $24^{\circ} \mathrm{C}$, 年日照百分率为 $56 \sim 64 \%$, 年平均日照总量维 持在 $2400 \sim 2900 \mathrm{~h}$ ，年降水量 500 750mm。由于玉 米生长条件的限制, 松辽平原玉米生长季节一般是从 5 月份持续到 9 月份，其中一些早玉米的播种日期会 更早一点。作物生长季 5-9 月的降水量由于季风气候 影响, 降水 $60 \sim 65 \%$ 集中在夏季。

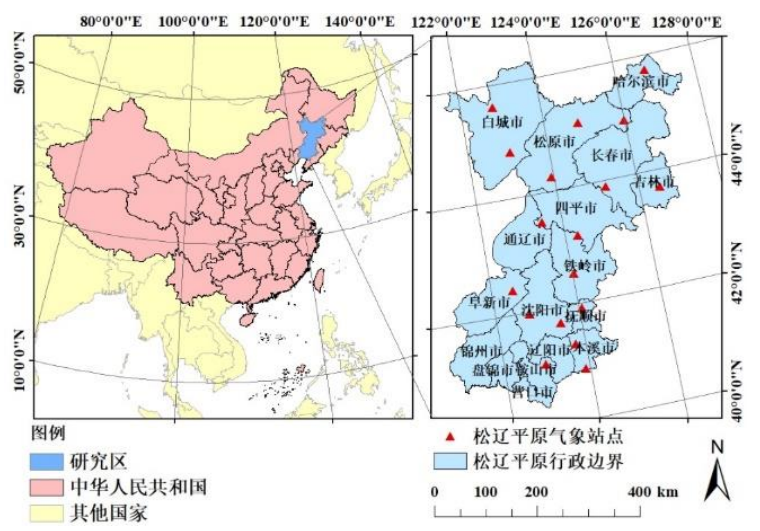

图 1 研究区地理位置图 


\section{3.数据和研究方法}

\section{1 数据来源}

本研究的气象站数据来自国家气象信息中心 (http://data.cma.cn/site/index.html), 包括松辽平原 18 个气象站(图 1)1956-2018 年的月平均气温和降水数 据。本文使用的未来气候情景数据由国际耦合模式比 较计划第五阶段 (Coupled Model Inter-comparison Project Phase 5 CMIP5）提供, 包括 1860-2100 年 5 个 气候模式: CanESM2、MIROC5、NorESM1-M、GFDLCM3、IPSL-CM5A-LR 历史和未来 2 个 RCP 情景(, RCP4.5、RCP8.5) 下温度和降水数据。以 1976-2005 为基准历史时段。由于全球气候模式的分辨率不同, 将不同分辨率的数据用双线性内插法统一插值到 $0.1^{\circ} \times 0.1^{\circ}$ 的网格上。产量数据从辽宁省、吉林省、黑 龙江省和内蒙古统计年鉴中获取, 包括 1981-2018 年 各地级市的玉米产量, 分别利用直线滑动均值法求取 趋势产量和气候产量。

\section{2 标准化降水蒸散指数 SPEI}

为了监测和研究全球增温背景下的干旱化过程, Vicente - Serrano $^{[6]}$ 等提出了标准化降水蒸散指数 (SPEI)。SPEI 指数既考虑了蒸散对温度敏感的特性, 又具备多尺度多空间比较的优点, 是气候变暖背景下 干旱监测与评估的理想指标, 被广泛应用于干旱研究 [7]，其具体计算过程见文献 ${ }^{[8]}$ 。

本文在参考《中国气象干旱图集（1956-2009)》 所记载的有关研究区历年干旱状况的基础上, 以国家 2017 年实施的气象干旱等级标准(GB/T20481-2017) 为依据, 制定出适应于研究区的 SPEI 干旱等级划分 标准 (表 1 )。

表 1 基于 SPEI 的干旱等级划分

\begin{tabular}{lll}
\hline 等级 & 类型 & SPEI \\
\hline 1 & 无早 & $-0.5<\mathrm{SPEI}$ \\
2 & 轻早 & $-1.0<\mathrm{SPEI} \leq-0.5$ \\
3 & 中旱 & $-1.5<\mathrm{SPEI} \leq-1.0$ \\
4 & 重早 & $-2.0<\mathrm{SPEI} \leq-1.5$ \\
\hline
\end{tabular}

\begin{tabular}{lll}
\hline 5 & 特早 & SPEI $\leq-2.0$ \\
\hline
\end{tabular}

\section{3 气候产量和干旱评估指标的计算}

研究干旱对农作物产量的影响就需要获得气候 产量。计算方式如下:

$Y_{c}=Y-Y_{t}$

式中, $Y$ 为实际单产, $Y_{t}$ 为趋势产量, $Y_{t}$ 为气象产 量, 是受以气候要素影响的波动产量分量, 能够反映 出逐年有利或不利的气候条件及其对产量的影响。

本文选取干旱频率为评估指标 ${ }^{[9]}$ 。干旱发生平率 是指某站点统计时间段内, 发生某等级干旱的次数与 总年数的比值。计算公式如下：

$D F=\frac{n}{N} \times 100 \%$

式中, $D F$ 为干旱发生频率, $N$ 为时间序列的总长 度, $n$ 为统计时段内 SPEI 满足某等级干旱强度的年 数, $D F$ 越大表明干旱发生越频繁。

\section{4 相关分析}

相关分析是描述两个变量的线性相关性的方法, 如有两个数据序列 $\mathrm{X}=\left\{\mathrm{x}_{1}, \mathrm{x}_{2}, \ldots \ldots, \mathrm{x}_{\mathrm{n}}\right\}$ 和 $\mathrm{Y}=$ $\left\{\mathrm{y}_{1}, \mathrm{y}_{2}, \ldots \ldots, \mathrm{y}_{\mathrm{n}}\right\}$ 两者的相关系数公式计算如下:

$\mathrm{r}=\frac{\operatorname{cov}(\mathrm{x}, \mathrm{y})}{\mathrm{S}_{\mathrm{x}} \mathrm{S}_{\mathrm{y}}}=\frac{\sum_{\mathrm{i}=1}^{\mathrm{n}}\left(\mathrm{x}_{\mathrm{i}}-\overline{\mathrm{x}}\right)\left(\mathrm{y}_{\mathrm{i}}-\overline{\mathrm{y}}\right)}{\sqrt{\sum_{\mathrm{i}=1}^{\mathrm{n}}\left(\mathrm{x}_{\mathrm{i}}-\overline{\mathrm{x}}\right)^{2} \sqrt{\sum_{\mathrm{i}=1}^{\mathrm{n}}\left(\mathrm{y}_{\mathrm{i}}-\overline{\mathrm{y}}\right)^{2}}}}$

式中, $S_{\mathrm{x}}$ 和 $\mathrm{S}_{\mathrm{y}}$ 为变量 $\mathrm{X}$ 和 $\mathrm{Y}$ 的标准差, $\operatorname{cov}(\mathrm{x}, \mathrm{y})$ 为 变量 $\mathrm{X}$ 和 $\mathrm{Y}$ 的协方差。相关系数 $r$ 的大小在-1.0 1.0之间, 当 $r>0$ 时表示两变量呈正相关关系，当 $r<0$ 时说明 两个变量呈负相关关系, $|\mathrm{r}|$ 越大说明两个变量之间的 相关性越强。

\section{4.结果分析}

\section{1 生长季气候因子与干旱指数变化}

玉米生长季适宜温度为 $25-31{ }^{\circ} \mathrm{C}^{[10]}$ ，通过对 1965 2018年松辽平原生长季各月和平均气温（图 2 a）变 化趋势分析发现, 近 54 年生长季平均气温均值为 $19.96^{\circ} \mathrm{C}$, 略低于玉米生长季所需温度。生长季7月份 平均值最高, 为 $23.78^{\circ} \mathrm{C}$, 最低是 9 月份, 为 $16.20^{\circ} \mathrm{C}$ 。 
生长季各月和平均气温总体呈上升趋势, 但增高幅度 明显不同。其中上升趋势最高为 9 月份 $(0.34 / 10 \mathrm{a})$, 最 低是7月份（0.20/10a), 而生长季平均气温以每10年 $0.26^{\circ} \mathrm{C}$ 速度变化。由(图2b)可知, 松辽平原5-9月降水 量为最高9月51.67mm到最低7月 $154.16 \mathrm{~mm}$, 生长季降 水量为 $480.64 \mathrm{~mm}$ 。1965-2018 年生长季降水量以每 10 年3.10mm的显著水平下降。近 54 年间减少了 $16.75 \mathrm{~mm}$ 。 从图 $2 \mathrm{~b}$ 还可以看出, 玉米生长季内 $5 、 6$ 月和 8 月降水 量呈缓慢上升趋势，7、9月降水量呈显著下降状态。 综上分析：1965-2018年松辽平原气温呈现上升趋势 而增暖显著, 降水量则呈显著下降趋势, 说明松辽平 原气候继续朝“暖干”方向发展。

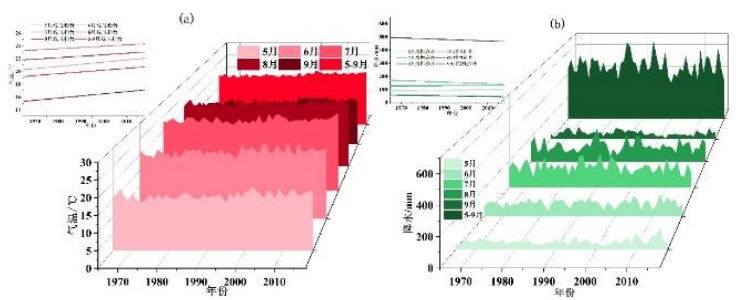

图 2 1965-2018 生长季和生长季各月气温(a)与降水 (b)时间变化趋势

图 3 为松辽平原 1965-2018 年生长季气温(a)降水 (b)空间变化趋势, 由图可知, 松辽平原各地都有明显 的增温趋势, 整个平原近 1965-2018 年平均升温为 $0.28^{\circ} \mathrm{C} / 10 \mathrm{a}$ 。大部分区域增温在 $0.25 \sim 0.35^{\circ} \mathrm{C} / 10 \mathrm{a}$ 之间。 增温趋势最大出现在松辽平原南部辽阳市 $0.42^{\circ} \mathrm{C} / 10 \mathrm{a}$, 最小出现在抚顺市 $0.15^{\circ} \mathrm{C} / 10 \mathrm{a}$ 。图 $3 \mathrm{~b}$ 为生长季降水 空间变化趋势图，降水空间分布不均匀，松辽平原 $60 \%$ 站点都有降水减少的趋势, 这些区域集中在松辽平原 南部和西北部, 而松辽平原东北地区显增加趋势为 $0 \sim 9.4 \mathrm{~mm} / 10 \mathrm{a}$ 。

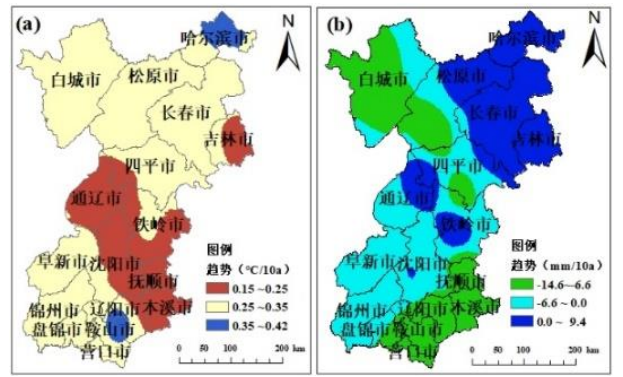

图 3 1965-2018 年生长季气温(a)降水(b)的空间变化趋 势
SPEI 能够描述不同时间尺度的旱涝演替，结合 SPEI 不同等级干旱划分能够评估研究区不同时间尺 度的不同类型干旱变化特征。由图 4 可以看出 1 和 3 个月短时间尺度的旱涝事件交替非常频繁, SPEI-1 和 SPEI-3 对短期温度降水的变化反映十分敏感（图 $4 a, b)$ 。随着 SPEI 时间尺度拉长，旱涝事件交替频率 降低, 呈现出较长的周期性。SPEI-6 和 SPEI-12 对短 期气温和降水的响应较弱, 干旱变化相对稳定。图 4d 显示, 松辽平原有两年左右的旱涝交替周期, 如 19651966、1970-1971，其中在 1985-1990、1998-2003 年 出现了两个 6 年左右的干旱期, 并有干旱化趋势。

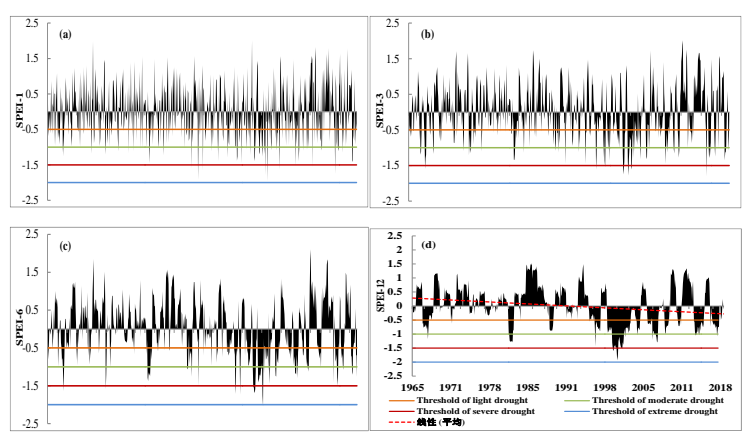

图 4 1965-2018 不同时间尺度 SPEI 波动图

\section{2 玉米气候产量与干旱指数相关性}

气候产量与 SPEI 相关性分析的结果能够反映产 量对不同时间尺度干湿变化敏感性的高低。气候产量 与短时间尺度 SPEI 之间的相关性较高, 所以本文选 取 SPEI-1 和 SPEI-3 与气候产量进行进一步分析。松 辽平原气候产量与 SPEI-1 的相关分析如表 2 所示。 玉米气候产量与大部分地区的 SPEI-1 呈正相关, 其 中 7 月份的 SPEI-1 与气象产量的相关性最高, 尤其 在白城市、阜新市、锦州市、和营口市 $(0.63, p<=0.01)$ 等地区, 松辽平原相关性达到 0.38。生长季平均 SPEI1 与气候产量的关系为营口市 $0.42(\mathrm{p}<=0.05)$, 松辽 平原达到 0.29 。这说明气候产量随着 SPEI 的降低而 降低, 也就是当气象条件越干, 产量随之下降。

1981-2018 年生长 SPEI-3 与松辽平原各地区气 象产量 Spearman 相关系如表 3 所示。除 5 月外, 其 他生长季月份与产量的相关性都较高, 这说明大部分 地区的干旱敏感期为生长季后期。 8 月的 SPEI-3 能 更好的反映气象产量。有两个地区 (营口市、白城市) 
的相关性分别达 0.66 和 $0.61 （ \mathrm{p}<=0.01 ）$, 松辽平原 为 $0.42(p<=0.05)$ 。除吉林市、鞍山市、本溪市、盘 锦市以外的其他地区大致与 SPEI-3 呈正相关。SPEI3 与 SPEI-1 相比, 与松辽平原气候产量的相关性更 强。

\section{3 全球变暖 $1.5^{\circ} \mathrm{C}$ 和 $2.0^{\circ} \mathrm{C}$ 气象因子变化}

为了客观地衡量 20 个 CMIP5 气候模式对松辽平 原年平均气温和年降水量的模拟能力, 分别计算了 1976-2005 年松辽平原年平均气温（年降水量）模拟 值与观测值之间的空间相关系数、标准误差和均方根 误差, 并将所有信息直观地绘制在泰勒图中 (图 5)。 如图 5 所示, 图中的彩色各种形状对应 20 个气候模 式, 横轴上的红点表示观测值。当模式点离观测点越
近时, 表明该模式的模拟能力越强。从图 5a 可以看 出, 各模式与观测值的气温相关系数在 0.41-0.91 之 间。而多模式集合 (MME) 对气温的模拟能力最好, 相关系数达 $0.90(p<0.01)$, 其标准差和均方根误差也 最接近观测值, 说明 MME 能较好的模拟研究区的气 温。MME 是 CanESM2、MIROC5 和 NorESM1-M 三个模式在等权重系数条件下的集合平均结果。从图 5(b)可知, 降水的模拟能力总体要比气温低, 20 个模 式的相关系在 0.29-0.70 之间, 均方根误差和标准差 在 100 左右波动, 但是相比之下 $\mathrm{MME}$ 的相关系为 0.64 , 标准差和均方根误差也是最小的。所以选取了 模拟能力较好的 CanESM2、GFDL-CM3 和 IPSLCM5A-LR 三个模式作为 MME。表 $4 \mathrm{a}$ 为所选 5 个模 式基本信息。

表 2 1981-2018 年松辽平原各市玉米生长季 SPEI-1 与气候产量的 Spearman 相关系数

\begin{tabular}{|c|c|c|c|c|c|c|c|c|c|c|c|c|c|c|c|c|c|c|}
\hline & 哈 & 白 & 长 & 吉 & 四 & 松 & 鞍 & 本 & 抚 & 阜 & 锦 & 辽 & 盘 & 沈 & 通 & 铁 & 营 & 松辽 \\
\hline 5 月 & -0.08 & -0.09 & -0.078 & 0.15 & 0.27 & -0.07 & -0.05 & -0.03 & -0.026 & -0.08 & -0.04 & -0.14 & -0.14 & -0.08 & -0.95 & -0.15 & -0.08 & -0.09 \\
\hline 6月 & 0.37 & 0.39 & $0.44^{*}$ & -0.03 & 0.3 & $0.44^{*}$ & 0.26 & -0.07 & -0.01 & 0.37 & $0.56^{* *}$ & -0.12 & 0.21 & 0.23 & 0.38 & 0.36 & $0.53^{* *}$ & 0.28 \\
\hline 7 月 & 0.38 & $0.53 * *$ & 0.15 & 0.06 & 0.33 & 0.16 & 0.24 & 0.17 & 0.21 & $0.48 *$ & $0.52 *$ & -0.05 & 0.22 & 0.31 & -0.12 & 0.25 & $0.63^{* *}$ & 0.38 \\
\hline 8 月 & 0.37 & $0.48^{*}$ & 0.29 & -0.9 & 0.1 & 0.38 & 0.37 & 0.21 & 0.22 & $0.44^{*}$ & 0.24 & 0.28 & 0.3 & 0.26 & 0.18 & -0.12 & $0.41^{*}$ & 0.31 \\
\hline 9 月 & 0.29 & 0.37 & 0.37 & 0.2 & -0.07 & 0.3 & -0.02 & 0.04 & -0.11 & 0.23 & -0.03 & -0.15 & -0.17 & 0.21 & -0.2 & -0.12 & 0.25 & -0.09 \\
\hline 平均 & 0.27 & 0.34 & 0.23 & -0.10 & 0.19 & 0.24 & 0.16 & 0.06 & 0.06 & 0.29 & 0.25 & -0.04 & 0.08 & 0.19 & -0.14 & 0.04 & $0.42 *$ & 0.29 \\
\hline
\end{tabular}

红色和蓝色分别表示正相关和负相关。 *相关性在 0.05 水平上显著(双尾)。**相关性在 0.01 水平上显著(双尾)。

表 3 1981-2018 年松辽平原各市玉米生长季 SPEI-3 与气候产量的 Spearman 相关系数

\begin{tabular}{|c|c|c|c|c|c|c|c|c|c|c|c|c|c|c|c|c|c|}
\hline 哈 & 白 & 长 & 吉 & 四 & 松 & 鞍 & 本 & 抚 & 阜 & 锦 & 辽 & 盘 & 沈 & 通 & 铁 & 营 & 松辽 \\
\hline-0.09 & 0.36 & -0.05 & -0.03 & 0.37 & -0.09 & -0.04 & -0.11 & 0.20 & 0.32 & 0.38 & 0.04 & -0.18 & -0.04 & 0.27 & 0.22 & -0.07 & 0.22 \\
\hline 0.33 & 0.36 & 0.30 & -0.12 & 0.30 & 0.37 & -0.05 & -0.08 & 0.23 & 0.38 & $0.64^{\star \star *}$ & 0.13 & -0.15 & 0.21 & 0.40 & 0.27 & 0.38 & 0.33 \\
\hline 0.31 & $0.46^{*}$ & -0.06 & -0.01 & 0.38 & 0.29 & -0.03 & 0.13 & 0.26 & $0.45^{*}$ & $0.58 * *$ & 0.03 & -0.07 & 0.24 & -0.08 & 0.24 & $0.61^{* *}$ & 0.23 \\
\hline $0.53^{* *}$ & $0.61^{* *}$ & 0.30 & 0.13 & 0.29 & $0.42 *$ & 0.28 & 0.17 & -0.02 & $0.59 * *$ & $0.50^{*}$ & 0.21 & 0.23 & 0.31 & 0.19 & 0.21 & $0.66^{* *}$ & 0.42 * \\
\hline $0.46^{*}$ & $0.52^{* *}$ & -0.01 & -0.07 & -0.03 & 0.30 & 0.32 & -0.15 & 0.15 & $0.51^{* * *}$ & 0.39 & 0.19 & 0.23 & 0.29 & -0.03 & 0.21 & $0.53^{* *}$ & 0.24 \\
\hline $0.48^{*}$ & $0.46^{*}$ & 0.22 & -0.18 & 0.38 & 0.29 & -0.01 & 0.17 & 0.20 & 0.50 & $0.51^{* *}$ & 0.11 & -0.05 & 0.29 & 0.16 & -0.03 & $0.55^{* *}$ & 0.24 \\
\hline
\end{tabular}

红色和蓝色分别表示正相关和负相关。 *相关性在 0.05 水平上显著(双尾)。**相关性在 0.01 水平上显著(双尾)。

表 4 所选 5 个模式基本信息(a)和不同排放情景达到 $1.5^{\circ} \mathrm{C}$ 和 $2.0^{\circ} \mathrm{C}$ 的时间表(b)（相对于 1976-2005） 
(a)

\begin{tabular}{lll}
\hline 模式 & 国家 & 分辨率 $\left(^{\circ}\right)$ \\
\hline CanESM2 & 加拿大 & $2.8^{\circ} \times 2.8^{\circ}$ \\
MIROC5 & 日本 & $1.4^{\circ} \times 1.4^{\circ}$ \\
NorESM1-M & 挪威 & $2.5^{\circ} \times 1.9^{\circ}$ \\
GFDL-CM3 & 美国 & $2.5^{\circ} \times 2.0^{\circ}$ \\
IPSL-CM5A-LR & 法国 & $3.8^{\circ} \times 1.9^{\circ}$ \\
\hline
\end{tabular}

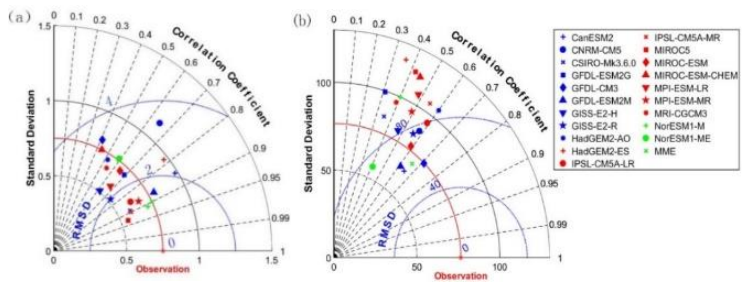

图 5 1976-2005 年 CMIP5 模式与观测的年平均气温 （a）与年降水量（b）泰勒图

为了减少模型之间差异和误差, 本文利用气温模 拟效果最佳的 3 个模型的 MME 来计算 RCP4.5 和 RCP8.5 两个排放情景下全球平均温度, 以确定全球 平均温度上升到 $1.5^{\circ} \mathrm{C}$ 和 $2.0^{\circ} \mathrm{C}$ 的阈值。相对于工 业化前（1861-1900）的水平,多模式集合在两个排放 路径下模拟全球平均气温达到 $1.5^{\circ} \mathrm{C}$ 和 $2.0^{\circ} \mathrm{C}$ 的时间 如表 $4 b$ 所示。

如图 6 所示, 2006-2100 期间, 在 rcp4.5 情景下, 气温有明显的上升趋势。最高气温和最低气温分别是 2072 年 $9.16^{\circ} \mathrm{C} 、 2006$ 年 $5.25^{\circ} \mathrm{C}$ 。全球变暖 $1.5^{\circ} \mathrm{C}$ 时, 研究区的平均气温达到 $6.03^{\circ} \mathrm{C}$; 当全球变暖 $2.0^{\circ} \mathrm{C}$ 时, 平均气温为 $6.81^{\circ} \mathrm{C}$ 。在 $\mathrm{rcp} 8.5$ 情景下, 气温以 $0.6^{\circ} \mathrm{C} / 10 \mathrm{a}$ 的速度在上升, 是 $\mathrm{rcp} 4.5$ 情景的两倍。最高 气温 $11.96^{\circ} \mathrm{C}$ 和最低气温 $5.82^{\circ} \mathrm{C}$ 分别出现在 2100 和 2007 年, 全球变暖 $1.5^{\circ} \mathrm{C}$ 和 $2.0^{\circ} \mathrm{C}$ 时, 平均气温分别 为 $6.72^{\circ} \mathrm{C} 、 7.29^{\circ} \mathrm{C}$ 。在同一情景下, $\mathrm{GW} 2.0$ 时的平均 值和极值都高于 GW1.5, 而在同一变暖情景下 rep8.5 值高于 rcp4.5。

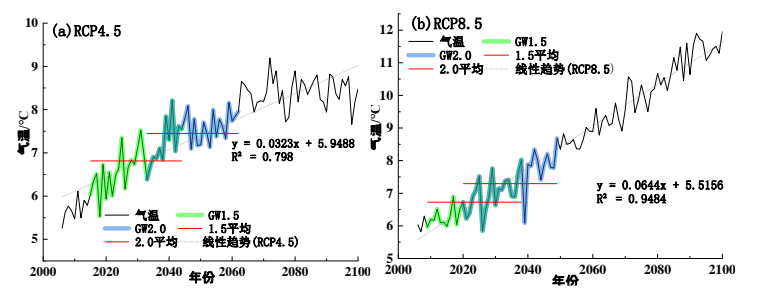

图 6 2006-2100 年不同排放情景下温度变化 (b)

\begin{tabular}{lcrl}
\hline 模式 & 升温 & 排放情景 & 升温出现时间 \\
\hline MME & $1.5^{\circ} \mathrm{C}(\mathrm{GW} 1.5)$ & RCP4.5 & $2015-2044$ \\
$($ (CanESM2+ & & RCP8.5 & $2033-2062$ \\
MIROC5 & $2.0^{\circ} \mathrm{C}(\mathrm{GW} 2.0)$ & RCP4.5 & $2009-2038$ \\
+NorESM1- & & RCP8.5 & $2020-2049$ \\
M)/3) & & & \\
\hline
\end{tabular}

如图 7 所示, 2006-2100 年期间, rcp4.5 情景下 每年以 $1.46 \mathrm{~mm} / \mathrm{a}$ 的速率在上升。2 100 年和 2015 年 出现最大降水 $925.26 \mathrm{~mm}$ 、最小降水 $560.49 \mathrm{~mm}$ 。全球 变暖 $1.5^{\circ} \mathrm{C}$ 和 $2.0^{\circ} \mathrm{C}$ 的平均降水为 $667.54 \mathrm{~mm}$ 和 $724.87 \mathrm{~mm}$; 在 $\mathrm{rcp} 8.5$ 情景下, 降水的上升速率为 $2.45 \mathrm{~mm} / \mathrm{a}$ 。最大降水量 2097 年 $920.46 \mathrm{~mm}$ 和最小降 水量 2014 年 $542.83 \mathrm{~mm}$ 。GW1.5 时, 平均降水量为 $645.16 \mathrm{~mm}$ 及当 $\mathrm{GW} 2.0$ 时, 平均降水量为 $670.89 \mathrm{~mm}$ 。 与 $\mathrm{rcp} 4.5$ 相比 $\mathrm{rcp} 8.5$ 情景下的全球变暖两个时段的 变化幅度较小。总结以往的全球增温研究结果, 全球 升温幅度越大, 对玉米生产带来的综合有害影响就越 大, 可能是因为气温升高幅度的增加引起蒸散量大, 虽然总的降水量在增加，但是升温导致的蒸散量程度 更加剧烈, 换而言之, 过高的增温幅度抵消了降水带 来的积极影响, 所以玉米生长季内干旱频发而影响产 量, 也有可能是由于相对于 $1.5^{\circ} \mathrm{C}$ 的升温 $2.0^{\circ} \mathrm{C}$ 升温情 景的高温灾害和强降雨等极端气候事件爆发的可能 性愈加显著，导致玉米减产风险增大。
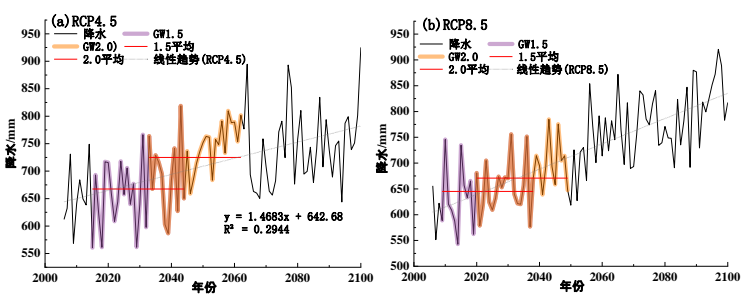

图 7 2006-2100 年不同排放情景下降水变化

\section{5.结论}

本文利用气象站点数据、产量数据和全球气候模 式数据, 采用 SPEI 干旱指数和相关性分析去探索松 辽平原干旱趋势干旱与产量之间的相关性以及全球 变暖 1.5 和 $2.0^{\circ} \mathrm{C}$ 时的气象因子情况, 主要结论如下:

（1）1965-2018 年间，松辽平原生长季各月和生 
长季气温都有上升趋势，其中 5-9 月的以 $0.26^{\circ} \mathrm{C} / 10 \mathrm{a}$ 速率呈增长趋势。生长季降水量以每 10 年 $3.10 \mathrm{~mm}$ 的 显著水平下降。近 54 年间减少了 $16.75 \mathrm{~mm}$ 。空间分 布上，增温趋势最大出现在松辽平原南部辽阳市 $0.42^{\circ} \mathrm{C} / 10 \mathrm{a}$,最小出现在抚顺市 $0.15^{\circ} \mathrm{C} / 10 \mathrm{a}$ 。降水空间 分布不均匀, 松辽平原 $60 \%$ 站点都有降水减少的趋 势。SPEI-1 和 SPEI-3 对短期温度降水的变化反映十 分敏感, 随着 SPEI 时间尺度拉长, 呈现出较长的周 期性。总体，松辽平原呈现“干暖化”趋势。

（2）1981-2018 年松辽平原玉米气候产量与 SPEI-1 和 SPEI-3 成正相关, 相对 SPEI-1 与 SPEI-3 的相关性更强。干旱指数越大, 气候产量越高。

（3）全球变暖 1.5 和 $2.0^{\circ} \mathrm{C}$ 情景时, 气温有明显 的上升趋势。在 $r c p 8.5$ 情景下, 气温以 $0.6^{\circ} \mathrm{C} / 10 \mathrm{a}$ 的 速度在上升, 是 rcp4.5 情景的两倍。在同一情景下, GW2.0 时的平均值和极值都高于 GW1.5, 而在同一 变暖情景下 $\mathrm{rcp} 8.5$ 值高于 $\mathrm{rcp} 4.5$ 。全球变暖 $1.5^{\circ} \mathrm{C}$ 和 $2.0^{\circ} \mathrm{C}$ 时, $\mathrm{rcp} 4.5$ 情景下每十年以 $14.6 \mathrm{~mm} / \mathrm{a}$ 的速率在 上升, rcp 8.5 情景下, 降水的上升速率为 $24.5 \mathrm{~mm} / 10 \mathrm{a}$ 。

\section{致谢}

本研究得到了国家重点研究开发计划 (2019YFD1002201)、国家自然科学基金(41877520)、 吉林省科技发展计划技术攻关项目 (20190303018SF)、吉林省科技发展计划重点研发 项目 (20200403065SF) 和长春市科技计划(19SS007) 的资助。

\section{参考文献}

[1] IPCC. Climate Change: The Physical Science Basis [M]. Contribution of Working Group 1 to the Fourth Assessment Report of the Intergovernmental Panel on Climate Change. Cambridge, UK: Cambridge University Press, 2007.

[2] IPCC., 2014. Climate change 2014: The physical science basis. Contribution of Working Group I to the Fifth Assessment Report of the Intergovernmental Panel on Climate Change[R]. Cambridge University Press, Cambridge, pp. 5-7.

[3] Molua E L. The economic impact of climate change on agriculture in Cameroon[J]. Social Science Electronic Publishing,2016, 6(9): 1-33.
[4] 张强,韩兰英,郝晓翠,等.气候变化对我国农业干 旱灾损率的影响及其南北区域差异性 [J].气象学 报,2015b,73(6):1092-1103.

[5] 张强,张良,崔显成,等.干旱监测与评价技术的发 展及其科学挑战 [J].地球科学进展.2011,6(7): 763-778.

[6] Vicente-Serrano S M, Cabello D, Tomas-Burguera $\mathrm{M}$, et al. Drought variability and land degradation in semiarid regions : Assessment using remote sensing data and drought indices (19822011)[J]. Remote Sensing, 2015, 7(4): 4391-4423.

[7] Zhang Q, Zhang J. Drought hazard assessment in typical corn cultivated areas of China at present and potential climate change[J]. Natural Hazards, 2016: $1-9$.

[8] Zhang Q, Zhang J, Wang C. Risk assessment of drought disaster in typical area of corn cultivation in China[J]. Theoretical and Applied Climatology, 2016: 1-8.

[9] Mitra S, Srivastava P. Spatiotemporal variability of meteorological droughts in southeastern USA[J]. Natural Hazards, 2017, 86(3): 1007-1038.

[10] 徐玉秀, 蒋姗姗, 周福然, 等. 198-2010 年锦州 地区玉米生育期气象因子变化及其 与气象产量 的关系 $[\mathrm{J}]$.气象 与环境 学 报, 2017, 33(5): 82-90. 